\title{
ESCLAVOS DE TEMPORALIDADES (EL TUCUMÁN, 1768): POSIBILIDADES DE UNA FUENTE DOCUMENTAL
}

\author{
POR \\ JoSÉ ANDRÉS-GALLEGO \\ Hispania Sacra
}

\section{RESUMEN}

Conclusiones del estudio cuantitativo de los inventarios de esclavos jesuíticos de tres jurisdicciones tucumanas: La Rioja, Santiago del Estero y San Miguel de Tucumán. El estudio demuestra las posibilidades que ofrece este tipo de fuentes.

\section{Amstract \\ Slaves of "Temporalidades" (El Tucumán, 1768): possibilities of a documental search. \\ Conclusions of a quantitative study on Jesuit slaves inventories in the three Tucuman. This study shows some possibilities that this type of document offers.}

La antropología histórica del mundo hispano en la plenitud del Antiguo Régimen en la que hemos centrado nuestra investigación en los últimos quince años ${ }^{1}$ requiere, es obvio, el conocimiento del universo esclavo, que constituía

1 Sobre ello hemos publicado, principalmente:

Historia general de la gente poco importante (Anérica y Europa hacia 1789), Madrid, Ed. Gredos, 1991, 459 págs. Versión italiana: Storia generale della gente poco importante: LEuropa $e$ 
una parte importante de ese mundo. Las fuentes para el estudio de la esclavitud son abundantes, como es bien sabido. Pero no siempre permiten una aproximación estadística a aspectos como la diversidad étnica de los esclavos, su profesión, su salud y los demás asuntos relativos a la demografía histórica.

Sin duda, los registros parroquiales son un vehículo de notable valor para llegar a algunos de estos aspectos. Pero no siempre existen -incluso existen pocas veces- y, en todo caso, deben agotarse todas las posibilidades que ofrecen fondos documentales complementarios.

Concretamente, un cauce para aproximarse a los aspectos cuantitativos del grupo humano constituido por los esclavos son los inventarios y tasaciones, de los cuales se efectuaron muchos a raíz de la expulsión de los jesuitas en 1767. Nuestro propósito en esta nota es explicar cómo hemos analizado los correspondientes a los colegios y estancias jesuíticos de La Rioja, San Miguel de Tucumán y Santiago del Estero ${ }^{2}$, por si la experiencia $(\mathrm{y}$ los resultados) sirven a otros estudiosos. La abundancia de la documentación de Temporalidades que existe en todo el mundo hispano- hace que este tipo de investigación sea especialmente asequible, naturalmente con medios informáticos, y necesaria para el conocimiento de uno de los grupos humanos más notables -y castigados por la historia- del Antiguo Régimen.

L'Anérica intorno al 1789, Milán, Sansoni, 1993, 306 págs. Versión portuguesa: História da gente pouco importante: América e Europa até 1789, Lisboa, Editorial Estampa, 1993, 305 págs.

Quince revoluciones y algunas cosas más, Madrid, Ed. Mapfre, 1992, 350 págs.

Cádiz y el pan de cada día, Cádiz, Universidad, 1995, 120 págs.

El fundamento epistemológico de esta investigación, en Recreación del humanismo: Desde la Historia, Madrid, Ed. Actas, 1994, 189 págs.

Además, "Derecho y justicia en América", "Afroamérica, la tercera ráz" e "Impacto en América de la expulsión de los jestitas", en Claves operativas para la historia de lberohmerica: Proyectos y actividades de la Fundación Mapfre América y del Instituto Histórico Tavera. Madrid, fundación Mapfre América y Editorial Mapfre, 1995, págs. 165-196, 241-284 y 309-360 respectivamente. Versión inglesa del primero, "Law and social change: the example of Latin America", en Valentín Vázquez de prada e Ignacio Olábarri (ed.); V Conversaciones Internacionales de Historia: Understanding social change in the nineties: theoretical approaches and historiographical perspectives, Aldershot, Variorum, 1995, págs. 319-346.

Tambiên, New History, notuvelle histoire: Hacia uma nueva historia, Madrid, Ed. Actas, 1993 , 245 págs. Con la colaboración de IgNACIO OLÁaARI GORTÁZAR, BronisLaW GEREMEK, ChaRLESOlivier Carbonell, Jack H. HeXter, Jörn Rusen, antonto Morales moya, Jesús de Garay,

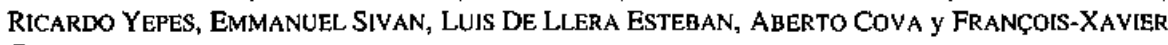
GUERRA.

2 Postura de esclavos que eran los jesuitas, 13 de agosto de 1768, AGT, sección judicial, Expedientes civiles, serie A, caja 23, exp. 6, f. 26-52v. La tasación de La Rioja (y por lo tanto el censo) se efectuó el 31 de julio. La de San Miguel de Tucumán, el 26. La de Santiago del Estero (que fue retasación), el 12 de noviembre.

Missionalia Hispanica

Hispania Sacra 48 (1996) 
Los inventarios en cuestión tienen una apariencia de suma pobreza: se reducen generalmente a un item por persona, de la que, sólo en dos o tres líneas, enumeran el nombre (y por tanto el sexo - que se puede ratificar con el género usado en otras palabras-), rara vez el apellido si es que lo tenía, el parentesco - en su caso- con el esclavo inmediatamente anterior en la lista, a veces la denominación étnica, la edad, las condiciones de salud cuando eran negativas, la especialización profesional si la había y el precio en que el esclavo se tasó.

Cada uno de estos aspectos (y otros que se pueden deducir de ellos: la edad a que se concibió el primer hijo conocido, el espacio intergenésico...) se ha traducido en un campo, en la base de datos con la que hemos operado.

En total, el número de indjviduos enumerados en los inventarios que estudiamos asciende a 497. De ellos, con seguridad, dos nacieron después de la expulsión de los jesuitas, mientras permanecían en poder de los administradores de las Temporalidades. Probablemente sucedió lo mismo con otros tres que, en el momento de la tasación, eran niños de pechos.

En el mismo periodo de dependencia de Temporalidades, murieron sin embargo tres de los de San Miguel de Tucumán y es posible que alguno más en Santiago del Estero y La Rioja, donde quizá no se hizo constar ese extremo.

En todo caso las sumas y las restas se compensaron.

$$
* * *
$$

De los 497, 274 pertenecían al colegio y estancias de La Rioja, 127 a los de San Miguel de Tucumán y 96 a los de Santiago de Estero

Lo primero que nos permite deducir era la tasa de masculinidad. En conjunto, eran 245 varones y 252 mujeres. La relación se situaba por tanto en 0,97 y 1,02 respectivamente. Distinguiendo entre los tres conjuntos humanos, el resultado sigue siendo visiblemente semejante:

\begin{tabular}{|c|c|c|c|}
\hline & VARONES & MUJERES & RELACIÓN \\
\hline La Rioja & 130 & 144 & $0.90 / 1 \times 10$ \\
\hline San Miguel de Tucumán & 64 & 63 & I'01/0'98 \\
\hline Santiago de Estero & 51 & 45 & l'13/0,88 \\
\hline
\end{tabular}


Esta "normalidad" de la relación parece decubrir no sólo el papel de la procreación en el desarrollo del grupo, sino probablemente la tendencia de los administradores a comprar esclavos que mantuvieran la relación numérica entre ambos sexos. Lo hacían posiblemente para mantener también las posibilidades de que se casaran entre ellos.

$$
\text { *** }
$$

Consta la denominación étnica de 362:

\begin{tabular}{|c|c|c|c|c|c|c|c|c|c|}
\hline & \multicolumn{2}{|c|}{ RIOJA } & \multicolumn{2}{|c|}{ S. MIGUEL } & \multicolumn{2}{|c|}{ SANT. } & \multicolumn{2}{|c|}{ TOTAL } & \multirow{2}{*}{$\frac{\text { TOTAL }}{\text { Vу }}$} \\
\hline & $\mathrm{v}$ & $M$ & $\mathrm{v}$ & $M$ & $\mathrm{v}$ & $M$ & $v$ & $\bar{M}$ & \\
\hline NEGROS & 50 & 55 & 24 & 12 & 11 & 3 & 85 & 70 & $=155$ \\
\hline MULATOS & 71 & 87 & 2 & 2 & 13 & 15 & 87 & 104 & $=191$ \\
\hline ZAMBOS & 4 & 1 & - & - & 5 & 5 & 9 & 6 & $=15$ \\
\hline ASPAÑOLADO & - & - & - & - & - & - & 1 & - & $=1$ \\
\hline
\end{tabular}

Al escribir aspañolado mantenemos -es obvio- la ortografía del documento, por mera fidelidad a las formas de decir de la época y del lugar.

De los llamados expresamente negros, hay 17 -todos en San Miguel de Tucumán- denominados negro angola y un negro de Guinea. De los diecisiete negros angola, 14 son varones y tres mujeres.

Entre los 191 mulatos, hay quince denominados mulatos zambos (que, por lo tanto, no incluimos entre los simplemente zambos, sino entre los mulatos). De estos mulatos zambos, diez son varones y cinco mujeres.

En suma, parece claro --a juzgar por la denominación étnica-- que la población esclava de San Miguel de Tucumán fuera de adquisición más reciente y más próxima a los orígenes africanos, en tanto que en la de La Rioja y Santiago del Estero abundaban más los mulatos, derivados de esclavos importados anteriormente y unidos a gentes de otras etnias. Esto último está ratificado por otra parte, en el caso de Santiago, de donde se nos dice expresamente que la mayoría eran mulatos y sambos aindiados (f.44).

Atención al significado étnico de este último adjetivo.

$$
* * *
$$

Conocemos la edad de 485. En bruto, les corresponde una media de 21'61 años. Es, pues una población eminentemente joven.

Missionalia Hispanica

Hispania Sacra 48 (1996) 
Los varones eran algo mayores que las mujeres: los 238 cuya edad conocemos tenía una media de 23'19; las 247 esclavas, $20^{\prime} 10$.

No había grandes variaciones regionales; pero sí las suficientes para añadir a lo dicho que la población de Santiago del Estero era - levemente- más vieja; detalle que insiste probablemente en una menor renovación - por menor compra- de la población esclava de la mencionada jurisdicción.

Concretamente, la edad media ascendía en La Rioja a 21'46, en San Miguel a 20'50, en Santiago a $23 ' 56$

Por sexos,

\begin{tabular}{|l|c|c|}
\cline { 2 - 3 } \multicolumn{1}{c|}{} & VARONES & MUJERES \\
\hline La Rioja & $23^{\prime} 15$ & $19^{\prime} 98$ \\
\hline San Miguel de Tucumán & $21^{\prime} 29$ & $19^{\prime} 69$ \\
\hline Santiago de Estero & $25^{\prime} 72$ & $21^{\prime} 06$ \\
\hline
\end{tabular}

La imagen del conjunto como una población notablemente joven está ratificada por la pirámide de edades, de la que sin embargo se deduce (1) una alta tasa de mortalidad infantil, que hace que la población casi se redujera a la mitad entre la primera y la segunda década, y (2) la tendencia - lógica por demás-a comprar esclavos en la edad más fértil desde el punto de vista laboral. Esa tendencia hacía que la cohorte de 21 a 30 años recuperase con creces lo perdido por la mortalidad infantil:

\begin{tabular}{|c|c|c|c|c|c|c|c|c|}
\cline { 2 - 10 } \multicolumn{1}{c|}{} & \multicolumn{2}{c|}{ LA RIOIA } & \multicolumn{2}{c|}{ S. MigUEL } & \multicolumn{2}{c|}{ SANTIAGO } & \multicolumn{2}{c|}{ TOTAL } \\
\hline EDAD & V & M & V & M & V & M & V & M \\
\hline $91 / 100$ & - & - & - & - & 1 & - & $\mathrm{I}$ & - \\
\hline $81 / 90$ & - & - & - & - & - & - & - & - \\
\hline $71 / 80$ & 3 & - & - & - & 1 & $\mathrm{I}$ & 4 & $\mathrm{I}$ \\
\hline $61 / 70$ & 2 & 4 & 1 & - & $\mathrm{I}$ & - & 4 & 4 \\
\hline $51 / 60$ & 5 & 5 & 5 & 5 & 4 & 2 & 14 & 12 \\
\hline $41 / 50$ & 14 & 3 & 2 & 3 & 1 & 2 & 17 & 8 \\
\hline $31 / 40$ & 15 & 14 & 7 & 5 & 8 & 2 & 30 & 21 \\
\hline $21 / 30$ & 22 & 41 & 10 & 10 & 10 & 13 & 42 & 64 \\
\hline $11 / 20$ & 24 & 34 & 17 & 15 & 5 & 7 & 46 & 56 \\
\hline $1 / 10$ & 39 & 41 & 22 & 24 & 19 & 16 & 80 & 81 \\
\hline
\end{tabular}

Missionalia Híspanica Hispania Sacra 48 (1996) 
Había, ya se ve, un individuo de cien años: Josef alias Chuchiquito, en Santiago del Estero.

En conjunto, las diferencias regionales nos impulsan a aventurar la hipótesis de una mayor longevidad masculina, a no ser que, en las compras de esclavos, se tendiera a comprar las mujeres con edad menor que la de los hombres. Esto, por lo demás, tendría sentido si se piensa que un varón no era eficaz más que desde el punto de vista laboral, y esto a partir de una edad relativamente avanzada, en tanto que las hembras añadian a su eficacia laboral la fertilidad, que, como veremos, era extraordinariamente precoz. Comprar mujeres jóvenes ofrecía una temprana reproducción

Se ratifica de otra parte la mayor juventud de la población esclava de San Miguel de Tucumán y se observa una tal estrechez en la cohorte santiagueña correspondiente a los 11/22 años, que hace pensar en una mortalidad infantil especialmente alta. El rasgo insiste en el mayor envejecimiento -étnico y biológico- del grupo santiagueño.

$$
* * *
$$

Los esclavos con calificación profesional son muy pocos. Y las profesiones representadas son las propias de las estancias agricolaganaderas, aparte el caso -muy destacable por su presencia en los tres lugares-de los músicos:

Dentro de su cortedad, abundan los carpinteros (9) y los albañiles (5), hay cocineros (dos) y un zapatero, un herrero, un hortelano, un barbero sangrador y un capataz de estancia. Y cuatro músicos, de ellos tres violinistas. Además, uno de los albañiles es cantor.

Adelantemos que se trata de los esclavos mejor cotizados. Concretamente, el precio más alto que se registra ( 260 pesos) corresponde al albañil cantor, a uno de los violinistas y a uno de los carpinteros.

A la imversa, los precios más bajos corresponden a los enfermos e impedidos, varios de los cuales ni siquiera se cotizaron en un solo peso.

No se descubren enfermedades típicas.

En La Rioja se dan bastantes casos (nueve) de mudos o fatuos.

Hay dos personas con mal gálico: una esclava de 25 años, madre, en San Miguel de Tucumán, y un violinista, casado también, en Santiago de Estero. Aunque la enfermedad se podía adquirir por herencia, su presencia obliga a considerar que la población esclava dependiente de religiosos no estaba necesariamente exenta de prácticas sexuales irregulares.

En lo mismo insiste la existencia de unos pocos casos - cuatro- de probable ilegitimidad en los hijos. 
Un análisis más detallado de lo relativo a la edad _-como el que aún vamos a intentar - tropieza con las limitaciones estadísticas que se indican en nota en el inventario que sigue a estas páginas. Con estas limitaciones penetramos en lo relativo a la fertilidad, que constituye un factor importante para comprender el comportamiento y la composición de este grupo humano.

La fuente que empleamos no nos permite conocer la edad en que contrajeron matrimonio los esclavos casados, pero - hasta cierto punto- nos deja aproximarnos a la edad en que concibieron el primer hijo conocido (sencillamente, restando — de la edad de cada cónyugue — la del hijo mayor y sumando 1 al resultado).

Haciendo así, la edad media en que procrearon su primer hijo conocido las 73 madres que forman nuestro grupo fue de $19^{\prime} 50$ años. La de los 72 padres (hay viudas y viudos y eso hace que no cuadren los números de unos y otros), $24^{\prime} 01$.

Sin La Rioja, las edades medias se cifran, respectivamente, en $20^{\prime} 6$ y $24^{\prime} 51$.

Ahora bien, el cálculo adolece de un inconveniente importante: que los inventarios no consignan como hijos aquellos que ya estaban casados. Los consignan solamente como cónyuges, por tanto como miembros de otro grupo familiar. De ahí que los hijos de veinte años o más sean excepcionales en nuestro documento.

Más aún: como veremos enseguida, había mujeres que concebían incluso a los once años y que, por tanto, dejaban de pertenecer al hogar - nominalmente - a esa edad tan temprana.

$\mathrm{Si}$-para evitar esta dificultad- calculamos la edad de la primera concepción sólo sobre el grupo de padres de menos de veinticinco años, la edad media de la primera concepción se reduce a 15 '60 en el caso de las mujeres y a $17 ' 36$ en el de los hombres.

Sin La Rioja, 16'66 y 15 respectivamente. Nos hallamos, por tanto, ante una nupcialidad extremadamente joven.

Y aún habría que añadir a esto el envejecimiento estadístico que impone la mortalidad infantil, que desconocemos completamente y que es más que probable que afectara también a los primogénitos. Conociendola, la edad de la primera concepción resultaría aún más temprana.

En este punto, y lamentablemente, no vale la pena entrar en distinciones entre cada una de las tres jurisdicciones representadas; la muestra de cada una de ellas sería demasiado pequeña para tener valor estadístico. 
Consignamos en cambio, a continuación, el número de mujeres que tuvieron su primer hijo conocido en cada edad:

\begin{tabular}{|c|c|c|c|}
\hline & & & sin La Rioja \\
\hline$A \operatorname{los} 11$ & años & 2 & 1 \\
\hline A $\operatorname{los} 12$ & “ & 6 & 3 \\
\hline$A \operatorname{los} 13$ & $“$ & 7 & 2 \\
\hline$A \operatorname{los} 14$ & $“$ & 5 & 3 \\
\hline$A \operatorname{los} 15$ & $“$ & 4 & 2 \\
\hline$A \operatorname{los} 16$ & $“$ & 5 & 2 \\
\hline$A \operatorname{los} 17$ & “ & 8 & 2 \\
\hline$A \operatorname{los} 18$ & “ & 5 & 4 \\
\hline A $\operatorname{los} 19$ & $*$ & 3 & - \\
\hline $\mathrm{A} \operatorname{los} 20$ & “ & 4 & 3 \\
\hline \multicolumn{2}{|c|}{ Con más de 20,' } & 24 & 13 \\
\hline
\end{tabular}

El Problema estadístico que señalábamos se reproduce si lo que pretendemos conocer es el espacio intergenésico, que resulta significativo para aproximarse un poco más al alcance de la mortalidad infantil. En este caso, además, el cálculo tiene que basarse en años y no en meses (puesto que no conocemos las fechas exactas de los nacimientos) y es por tanto menos exacto.

Con estas salvedades, sin contar los diez años que mediaron entre un enfermo de llagas - que permaneía con sus padres a los veinte años-y el hermano que le seguía en el hogar, por ser excepcional la permanencia de aquél, el espacio intergenésico resultante en el conjunto es de 3'21 años. Si excluimos también La Rioja, ${ }^{\prime} 52$.

Se trata de una tasa alta, muy superior a la normal en una natalidad natural. Presuponiendo que no había contracepción, habla a las claras de una mortalidad infantil elevada, si bien hay que tener en cuenta, de nuevo, que la tasa está modificada - también en este caso- por la juventud de la nupcialidad femenina, que sabemos no hacía figurar como tales a las hijas casadas ya.

$$
* * *
$$

Por lo demás, los mismos inconvenientes presenta el cálculo del número medio de hijos por familia. En realidad sólo conocemos los que no se habían emancipado de una u otra manera. Con esta salvedad, hay que decir que la tasa es sumamente baja: 1'51 hijos por matrimonio; sin La Rioja, 1'30.

Missionalia Hispanice

Hispania Sacra 48 (1996) 
$\mathrm{Si}$, para obviar en lo posible el inconveniente que acabamos de indicar, nos reducimos a los hijos de los matrimonios cuya esposa tenía menos de 25 años en el momento de hacer el inventario, el problema es inverso: conoceremos sólo los hijos que tuvieron hasta esa edad (que, ciertamente, no marcaba el fin de la fertilidad normal de una mujer). Pero el cálculo vale la pena porque, teniendo en cuenta nuevamente la juventud de la nupcialidad, la tasa vuelve a resultar abrumadoramente baja: 1'14 hijos; sin La Rioja, 1'61.

Este último cálculo ya no deja a dudas sobre el notable alcance de la mortalidad infantil.

$$
* * * 3
$$

Al referimos a la primera concepción, nos hemos aproximado ya, en lo posible, a la temprana edad en que tendían a contraer matrimonio. Añadamos que hay dos casos seguros de varones casados con libre, los dos de Santiago del Estero y ambos en segundas nupcias. Hay asimismo dos mujeres, de La Rioja, casadas con libre, y otra probable en San Miguel.

Por razones seguramente de pudor (tenían hijos), la fuente advierte quiénes eran viudas: cinco mujeres. Aparte había cuatro probables viludos (más los dos casados por segunda vez).

Acabemos con el valor dinerario de los esclavos. Excluimos los que no tenían ninguno, porque eran inservibles. La media de los demás (475) se eleva a 149'04 pesos: $150^{\prime} 42$ los varones y $147^{\prime} 70$ las hembras.

Las diferencias sin embargo eran grandes: valían poco los niños, menos cuanto más jóvenes (hasta setenta pesos tan sólo, por sanos que estuvieran), sin duda porque pendía sobre ellos la espada de la mortalidad infantil. Y menos asimismos los más viejos y los que tenía algún defecto físico que les impidiera rendir al máximo. Más, por el contrario, los especializados. Que también constituían una excepción.

Ciñámonos, por tanto, al valor medio de los esclavos sin oficio ni enfermedad y con una edad comprendida entre los 20 y los 40 . El resultado global es $198^{\circ} 09$ pesos (y doscientos pesos es, en efecto, la cantidad consignada con más frecuencia en los inventarios): lo mismo los varones (199'23) que las hembras (197'29).

Interesa conocer las diferencias étnicas (siempre, de los esclavos sin enfermedad ni especialización, y entre 20 y 40 años):

$\begin{array}{ll}\text { NEGROS } & 196^{\prime} 08 \\ \text { NEGRAS } & 191^{\prime} 53\end{array}$




$\begin{array}{ll}\text { MULATOS } & 193^{\prime} 94 \\ \text { MULATAS } & 200 \\ \text { ZAMBOS } & 235 \\ \text { ZAMBAS } & 235\end{array}$

La verdad es que la muestra de esos últimos (un zambo y dos zambas) es demasiado pequeña y el resultado es inverosímil. El defensor fiscal nombrado para la tasación de Santiago del Estero nos dice de hecho que los mulatos y sambos aindiados, que es lo que eran, como sabemos, la mayoría de los esclavos jesuíticos de aquella jurisdicción, valían una tercera parte menos que los negros, según la estimación común del comercio, y que los tasadores de Santiago se habían excedido en los precios.

Por otra parte, allí los esclavos debían costar más, cualquiera que fuese su color, a juzgar por el hecho de que los negros bozales (o sea los recién importados a América), que se valoraban en San Miguel en doscientos pesos, valían en Santiago 280, incluso 300 (f. 44).

Aquellos mulatos y sambos aindiados del Estero, añadía el fiscal, eran inútiles para el cultivo y manejo de las haciendas. Pero convenía venderlos, no sólo por lo que costaba mantenerlos, sino por el peligro de que murieran, enfermaran o se fugasen "y reselarse alguna sublevación de que ya tiene $\mathrm{VS}^{\mathrm{a}}[\mathrm{el}$ gobernador y capitán general de la provincia] comprobante, de los que por ese delito se hallan presos" (f. 44v). Razón por la que aconsejaba que se retrasaran a la baja, como en efecto se hizo.

Aun así, los precios de Santiago continuaron siendo más altos que los de La Rioja y San Miguel.

$$
* * *
$$

¿Vale la pena el trabajo? Nos parece que sí. El futuro de la historia afroamericana depende en buena parte de la ampliación de las fuentes que suelen emplearse. Los recuentos del tráfico de esclavos y los registros parroquiales - por citar dos documentos típicos hasta hoy, y efectivamente valiosos- no agotan desde luego las posibilidades de crear estadísticas que permitan conocer aspectos de la vida de aquellas gentes.

Los inventarios y tasaciones de Temporalidades tampoco resuelven las carencias de los documentos más usuales pero constituyen una contribución estimable. 

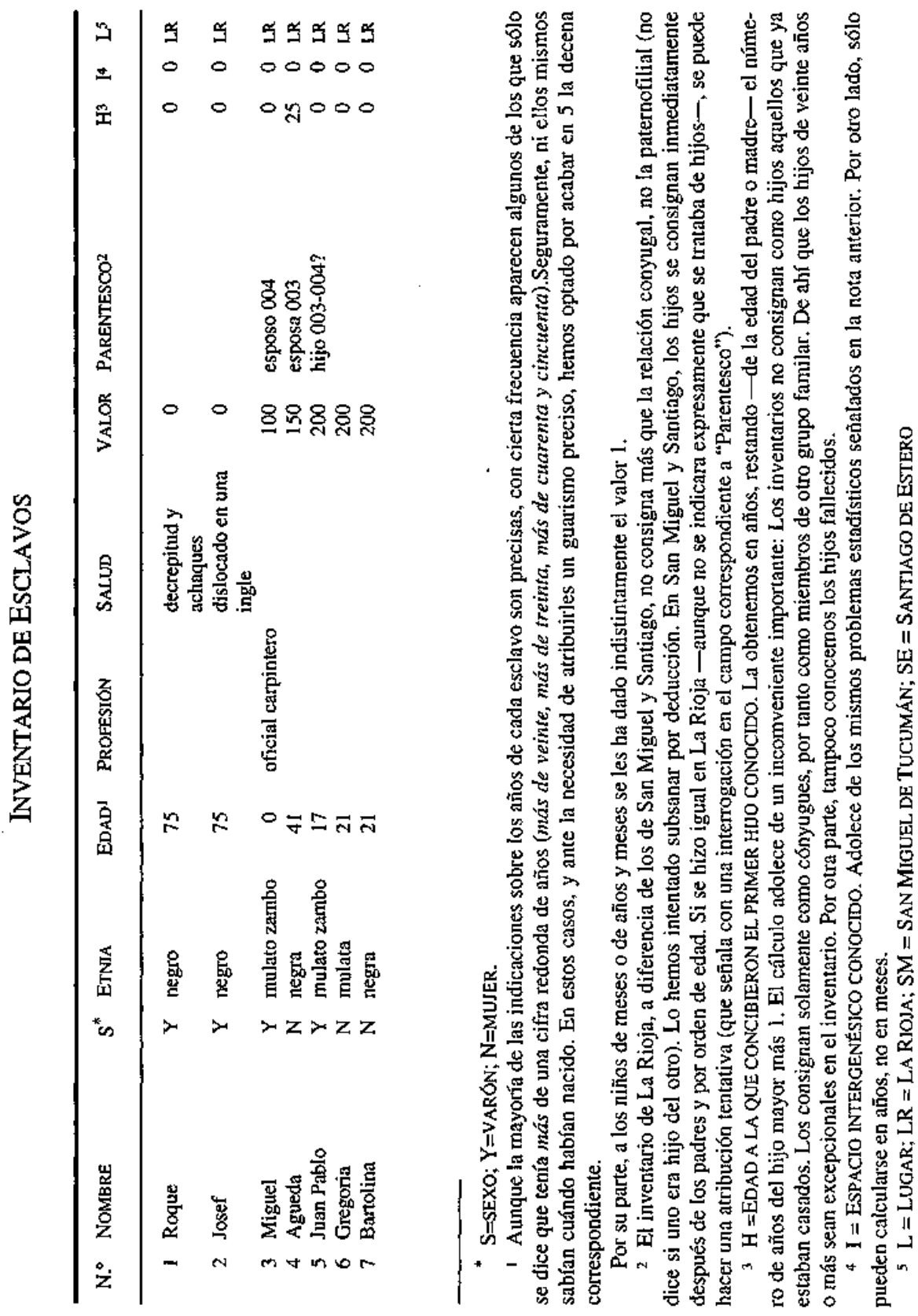

Missionalia Hispanice

Hispania Sacra 48 (1996) 


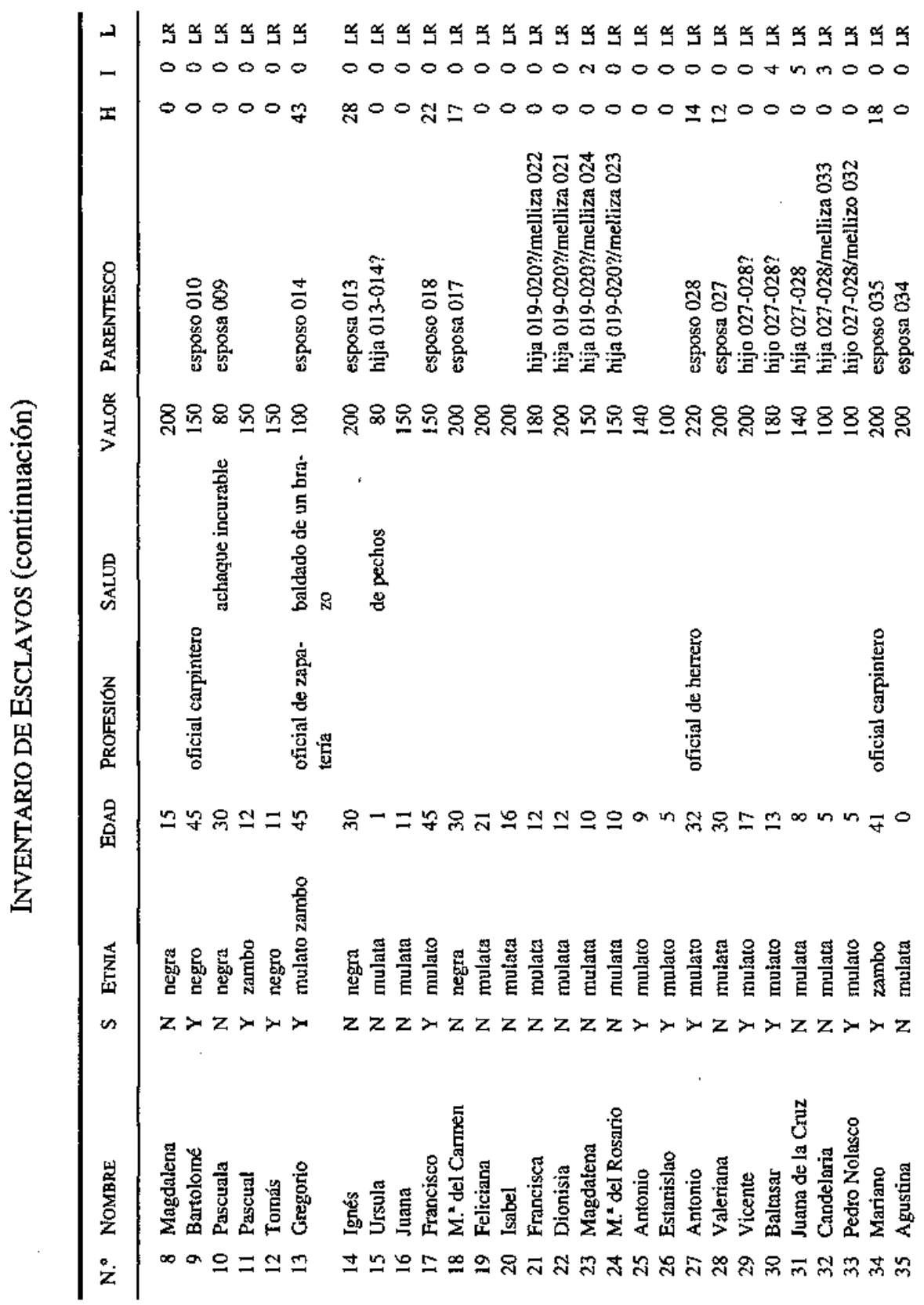

Missionalia Hisparica

Hispania Sacra 48 (1996) 


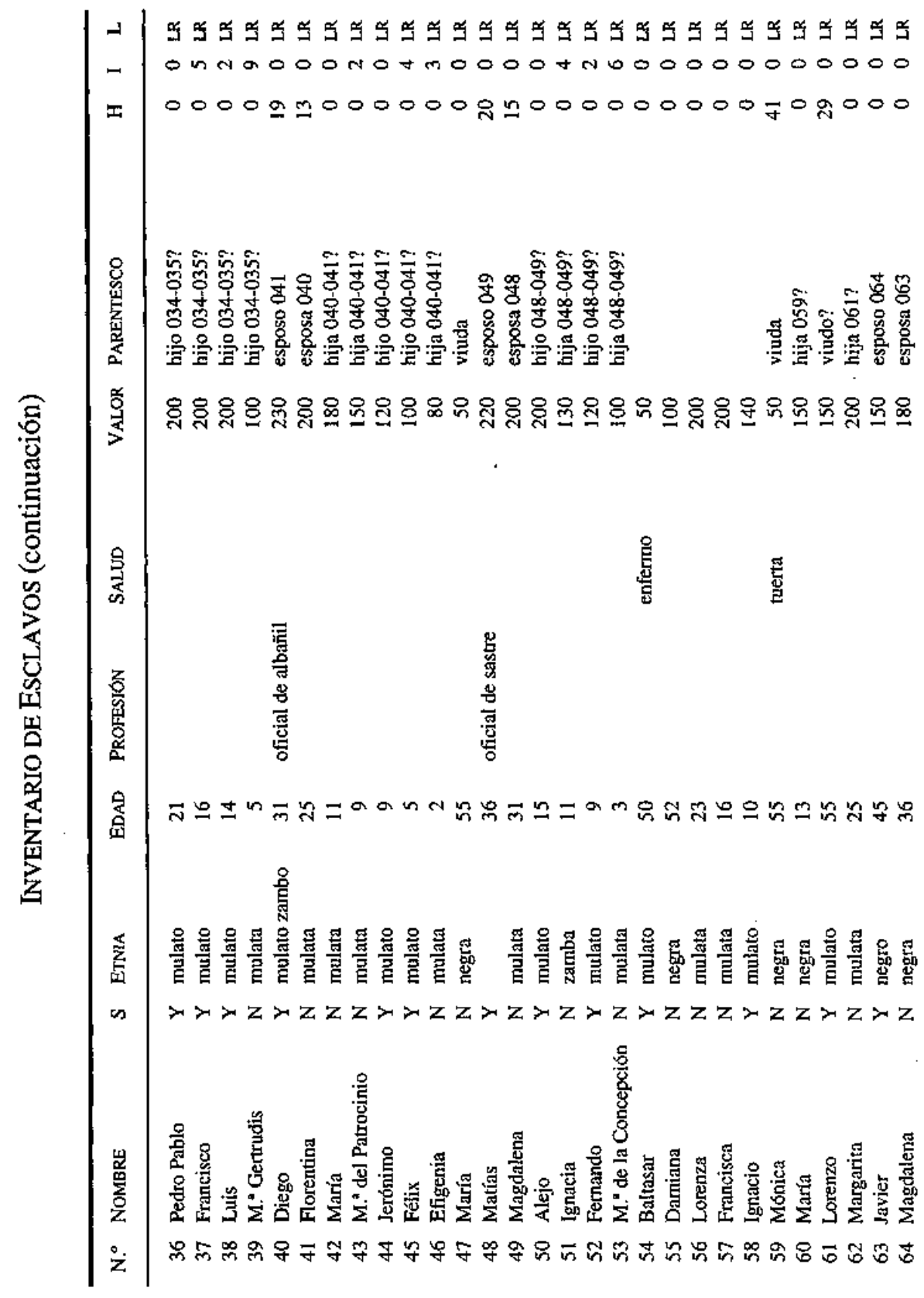

Missionalia Hispanica Hispania Sacra 48 (1996) 


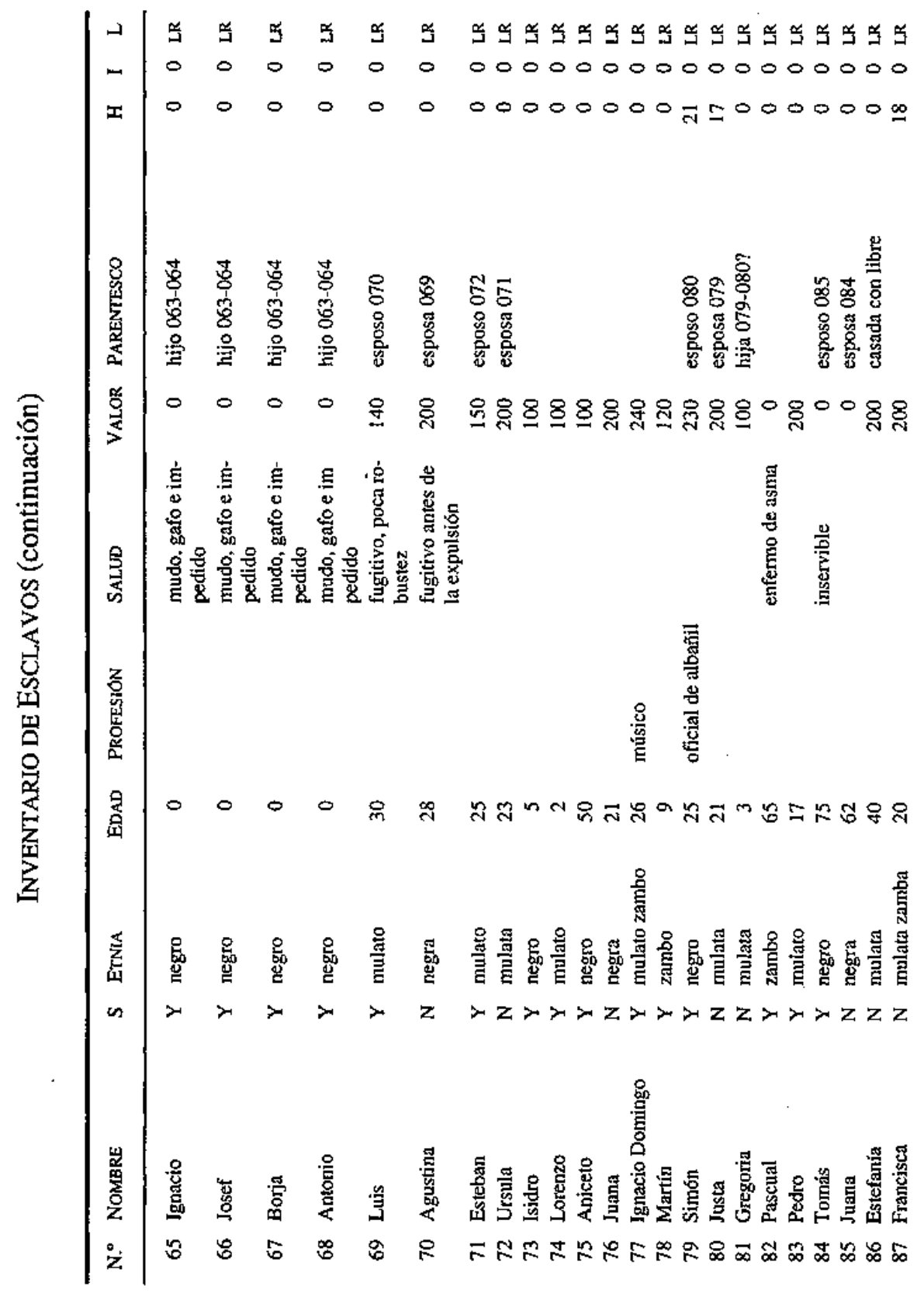

Missionalia Hispanica

Hispania Sacra 48 (1996) 


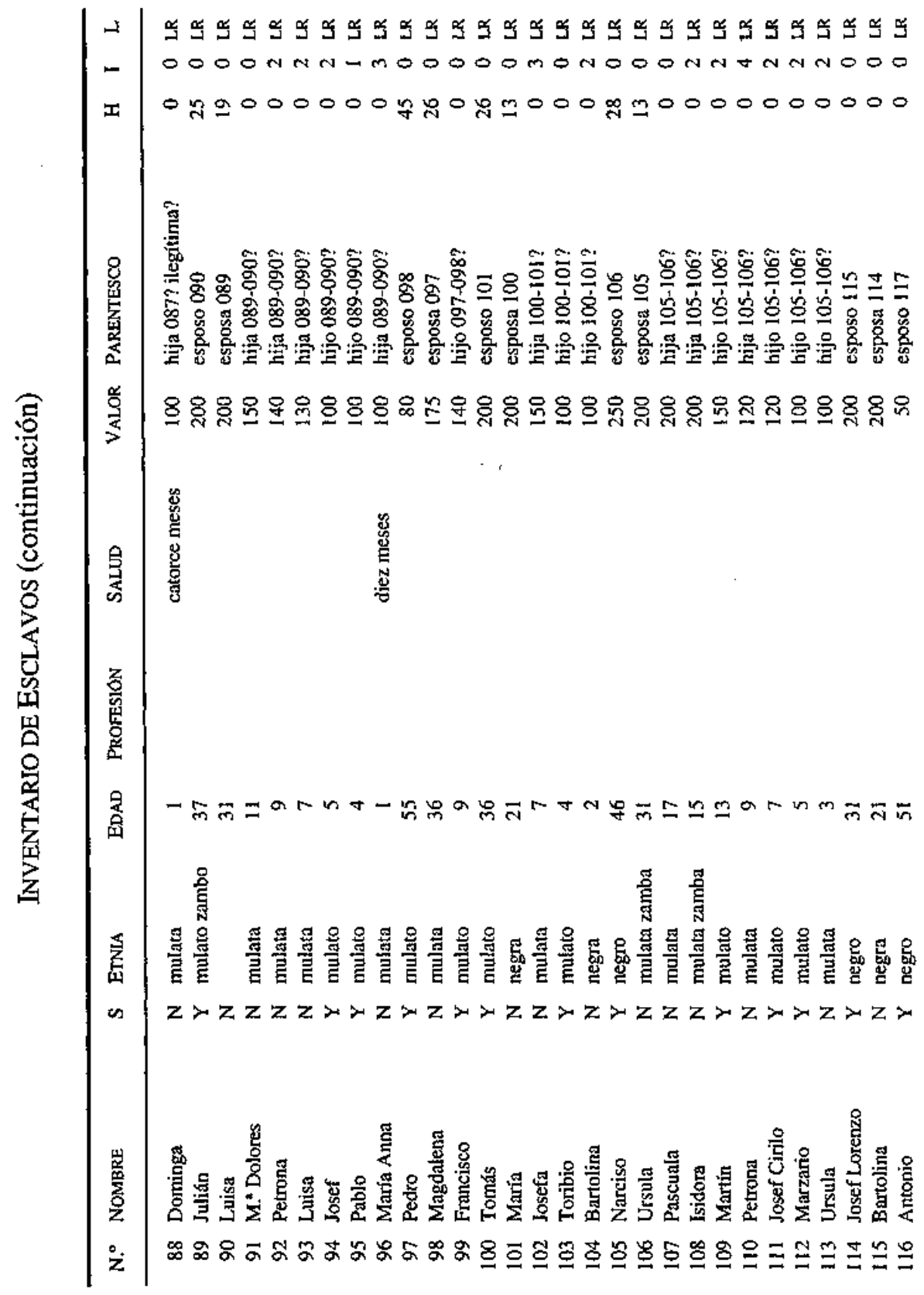

Missionalia Hispanica Hispanin Sacra 48 (1996) 


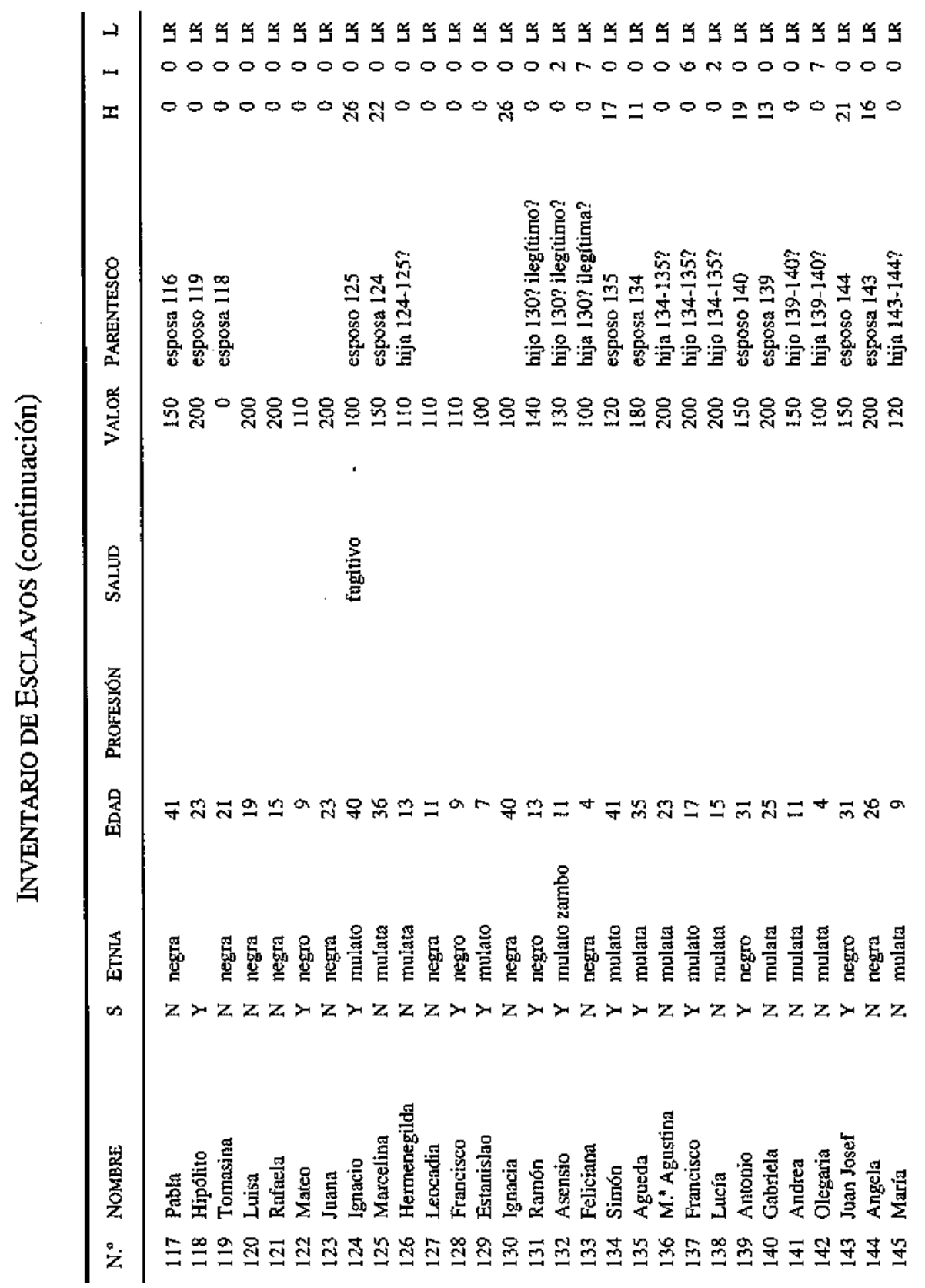

Missionalia Hispanica

Hispania Sacra 48 (1996) 


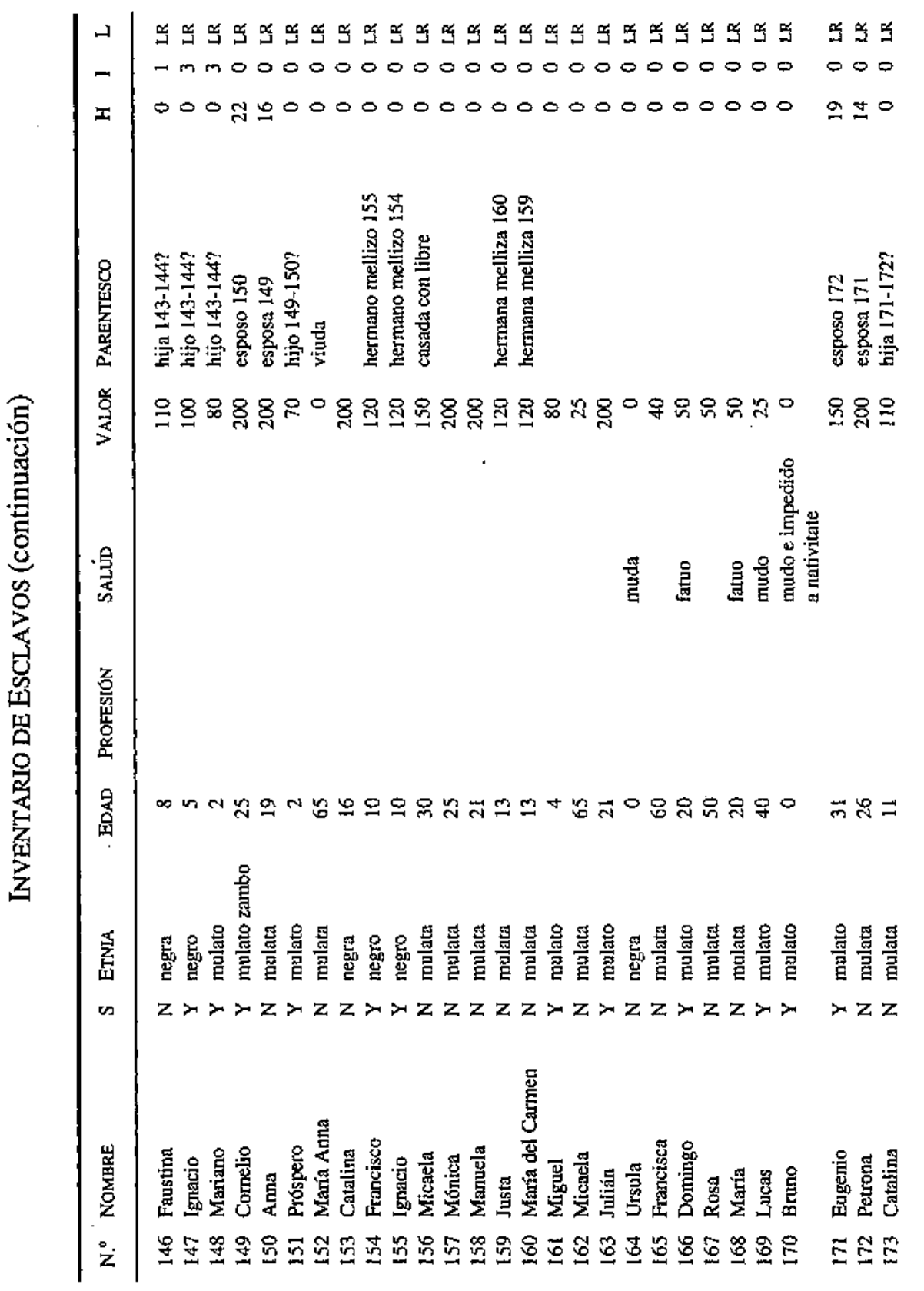

Missionalia Hispanica Hispania Sacra 48 (1996) 


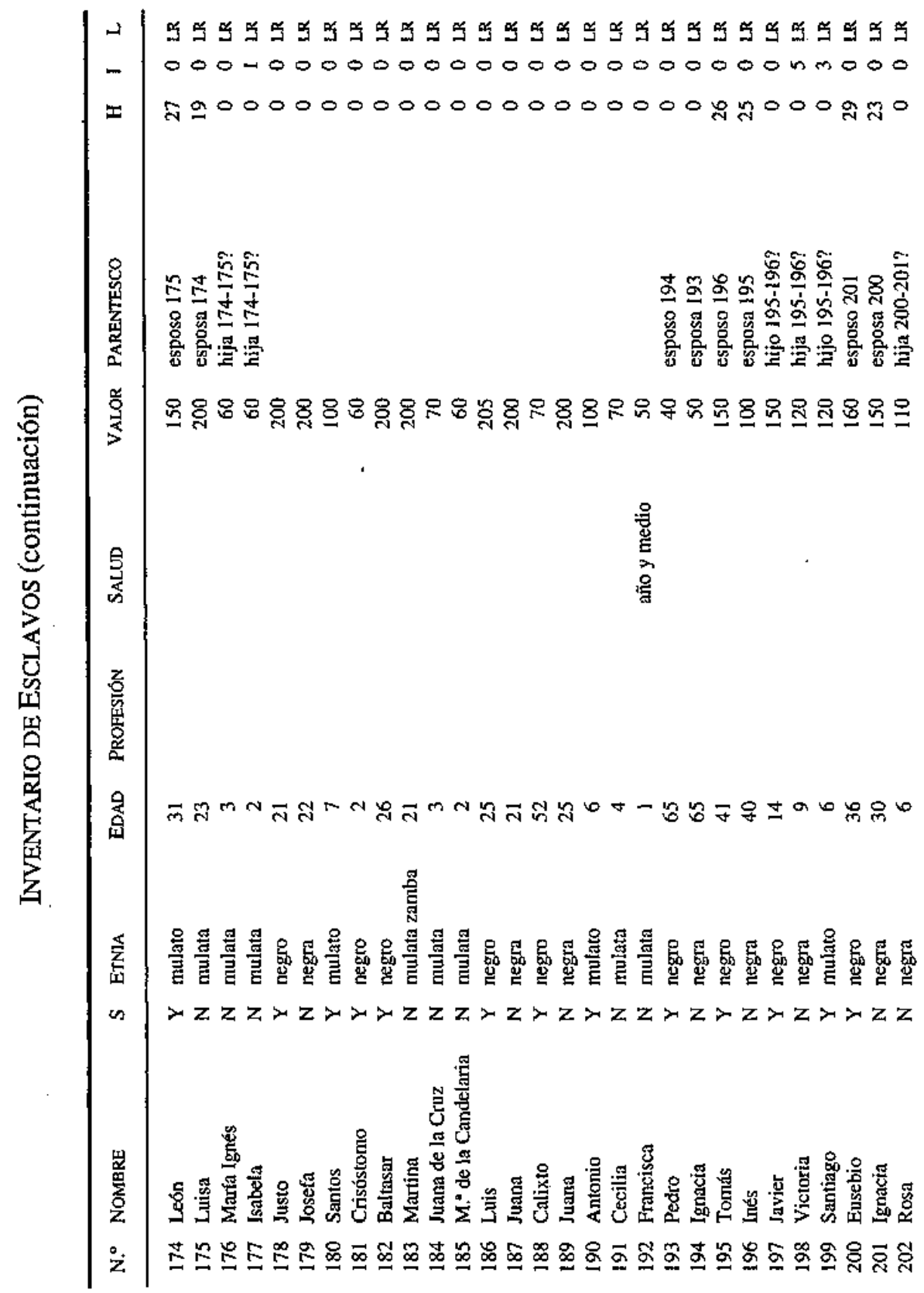

Missionnlia Hispanica

Hispania Sacra 48 (1996) 


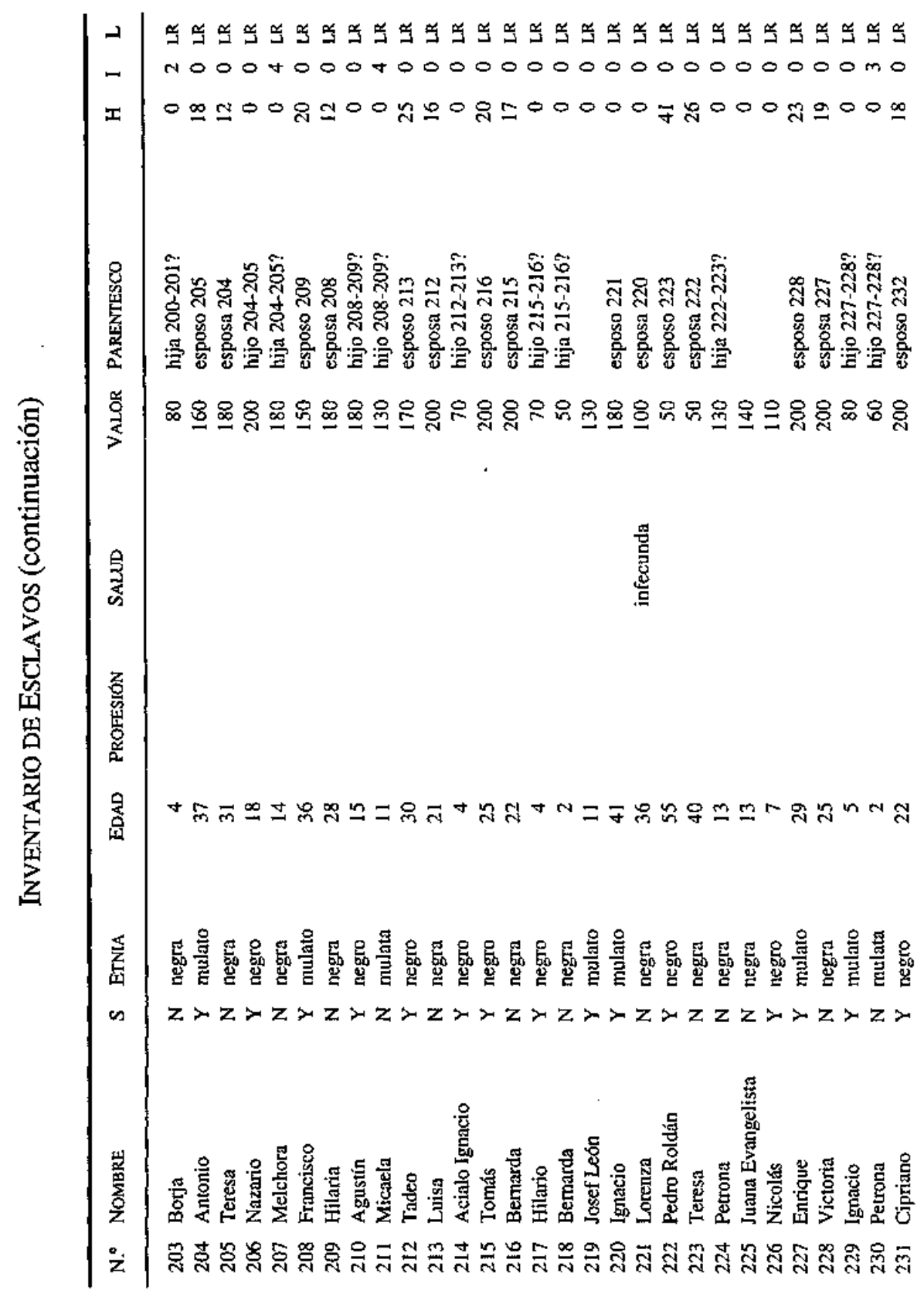

Missionalia Hispanica Hispania Sacm 48 (1996) 


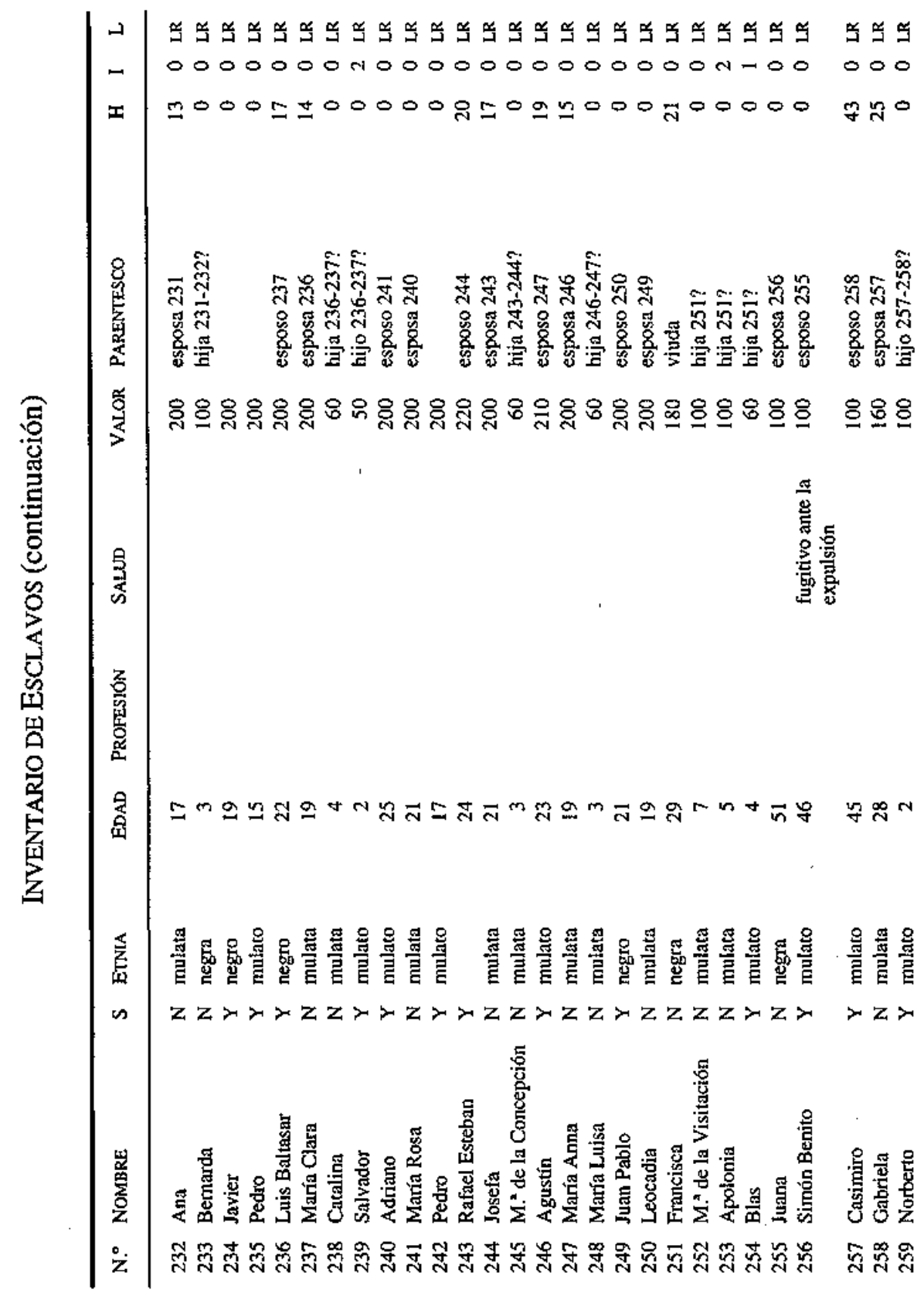

Missionalia Hispanica

Hispania Sacra 48 (1996) 
ESCLAVOS DE LAS TEMPORALIDADES (EL TUCUMÁN, 1768)

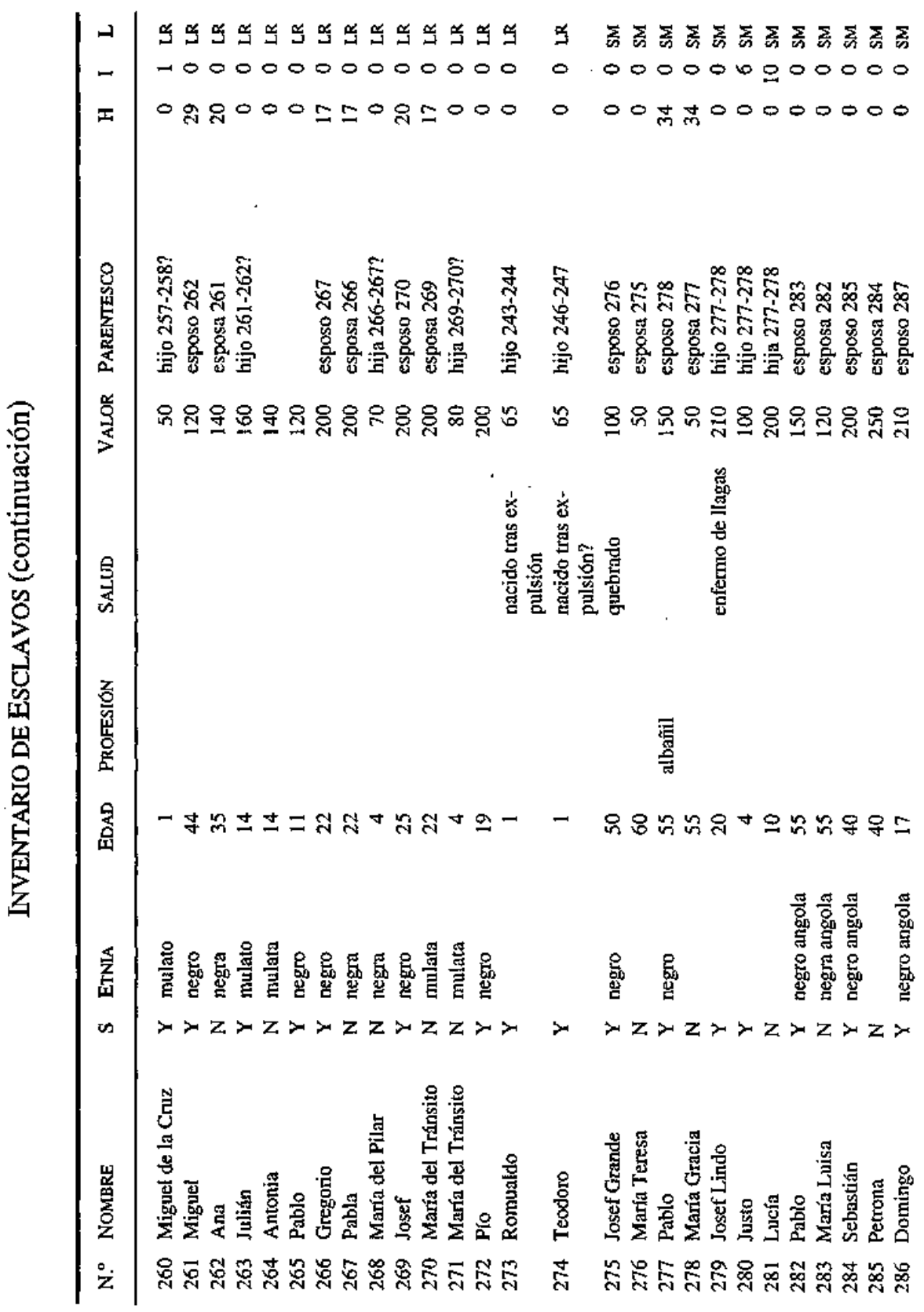

Missionalia Hispanica Hispania Sacra 48 (1996) 


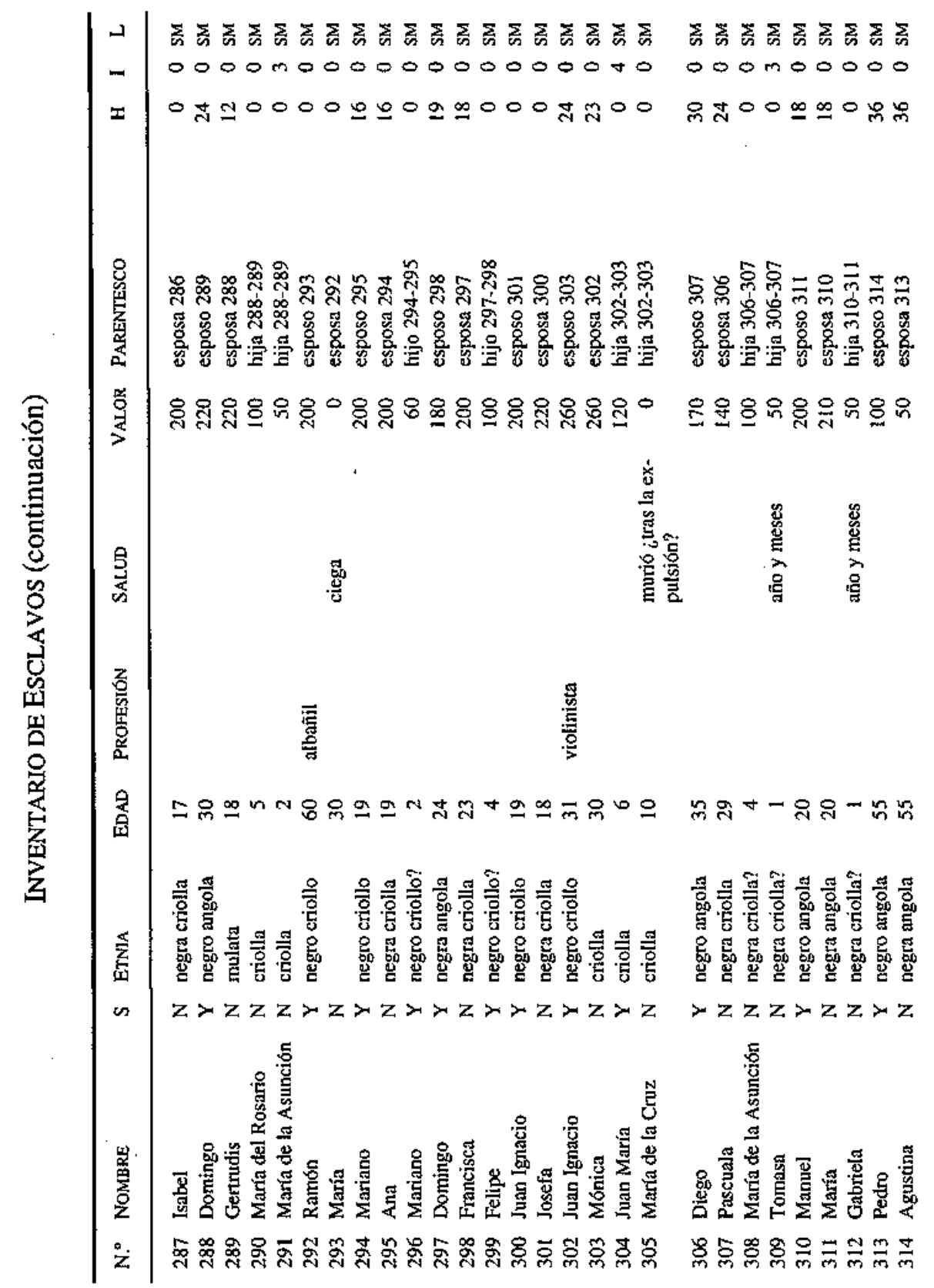

Missionalia Hispanica

Hispania Sacra 48 (1996) 
ESCLAVOS DE LAS TEMPORALIDADES (EL TUCUMÁN, 1768)

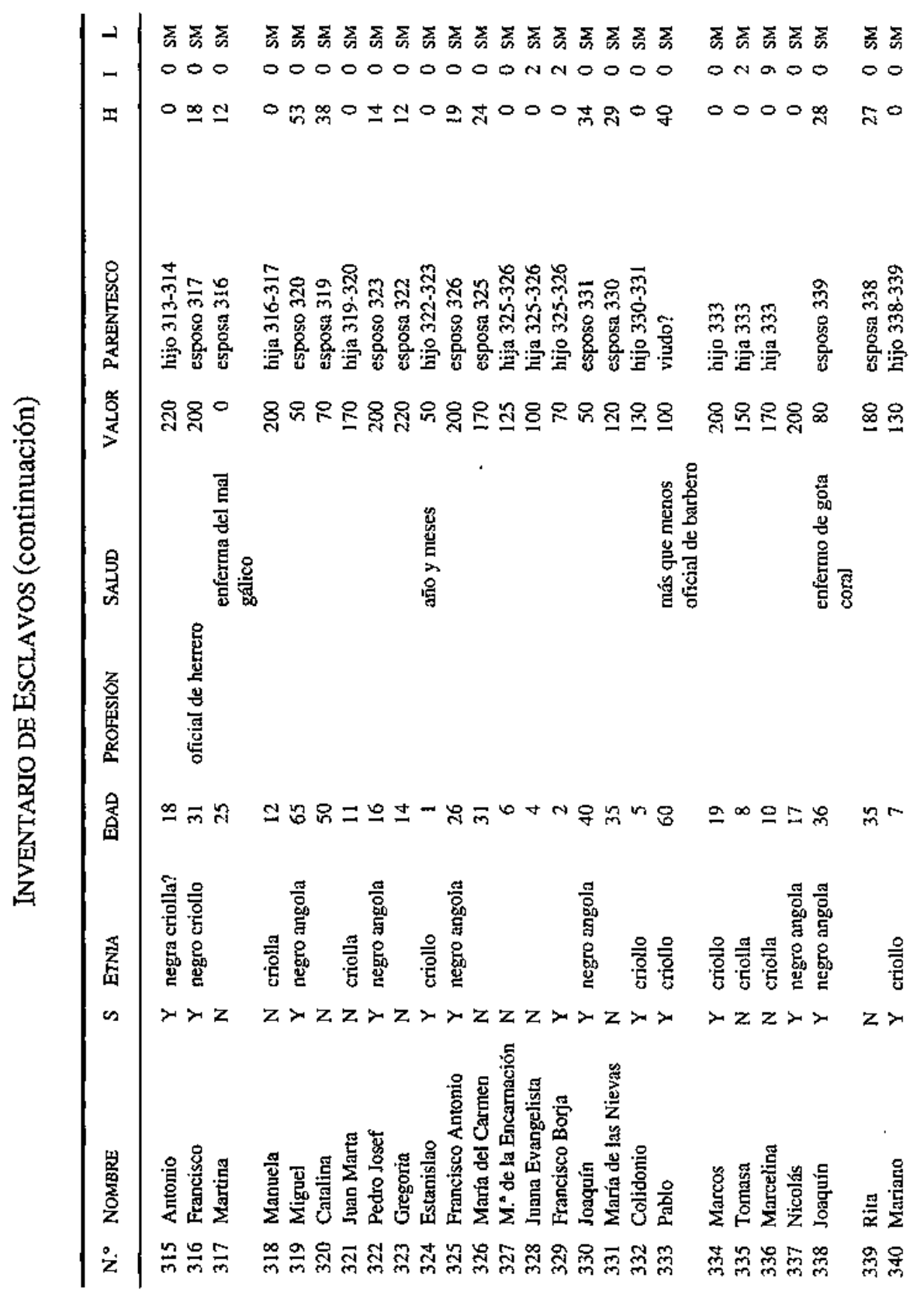

Missionalia Hispanica Hispania Sacra 48 (1996) 


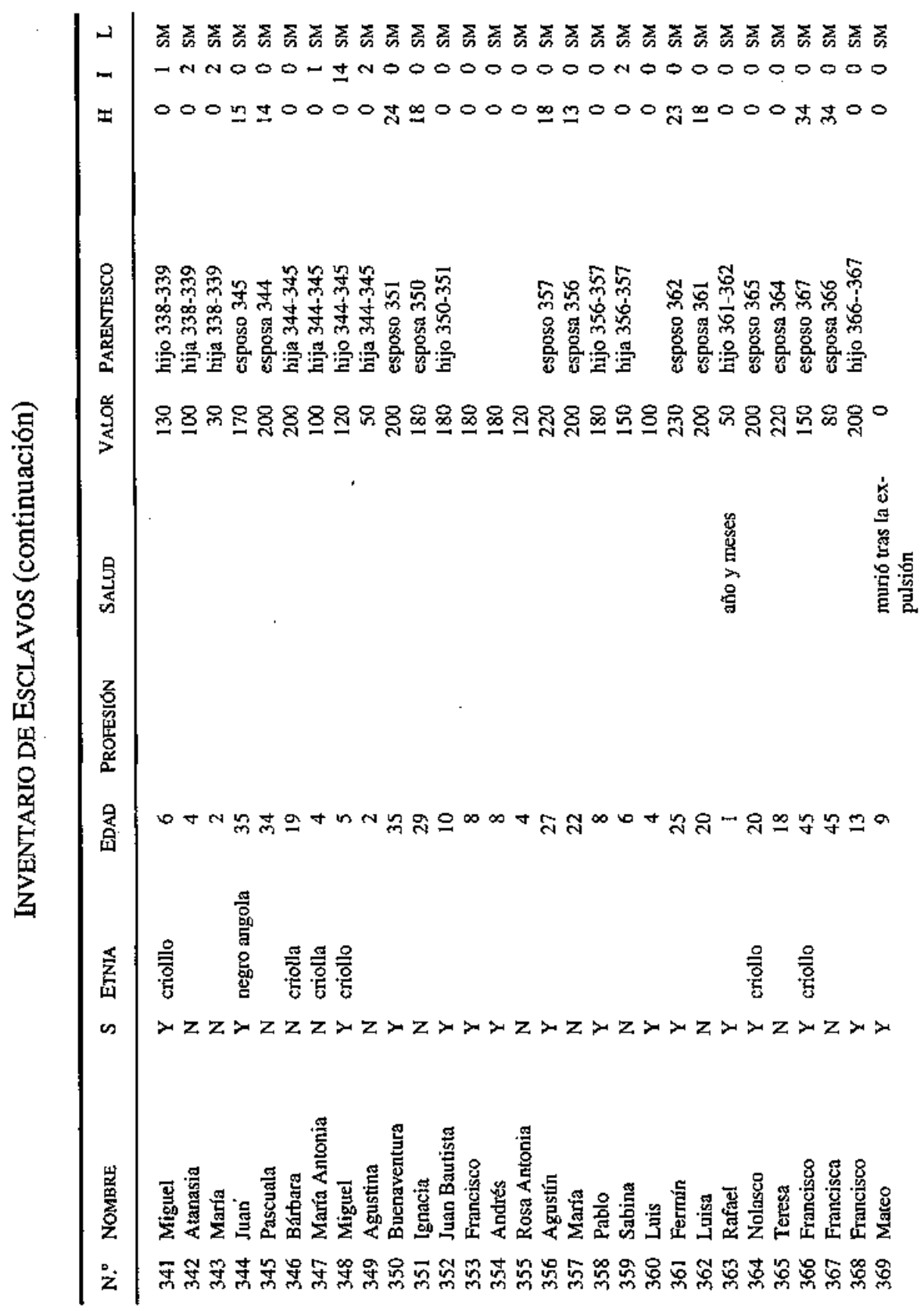

Missionajia Hispanica

Hispania Sacra 48 (1996) 
ESCLAVOS DE LAS TEMPORALIDADES (EL TUCUMÁN, 1768)

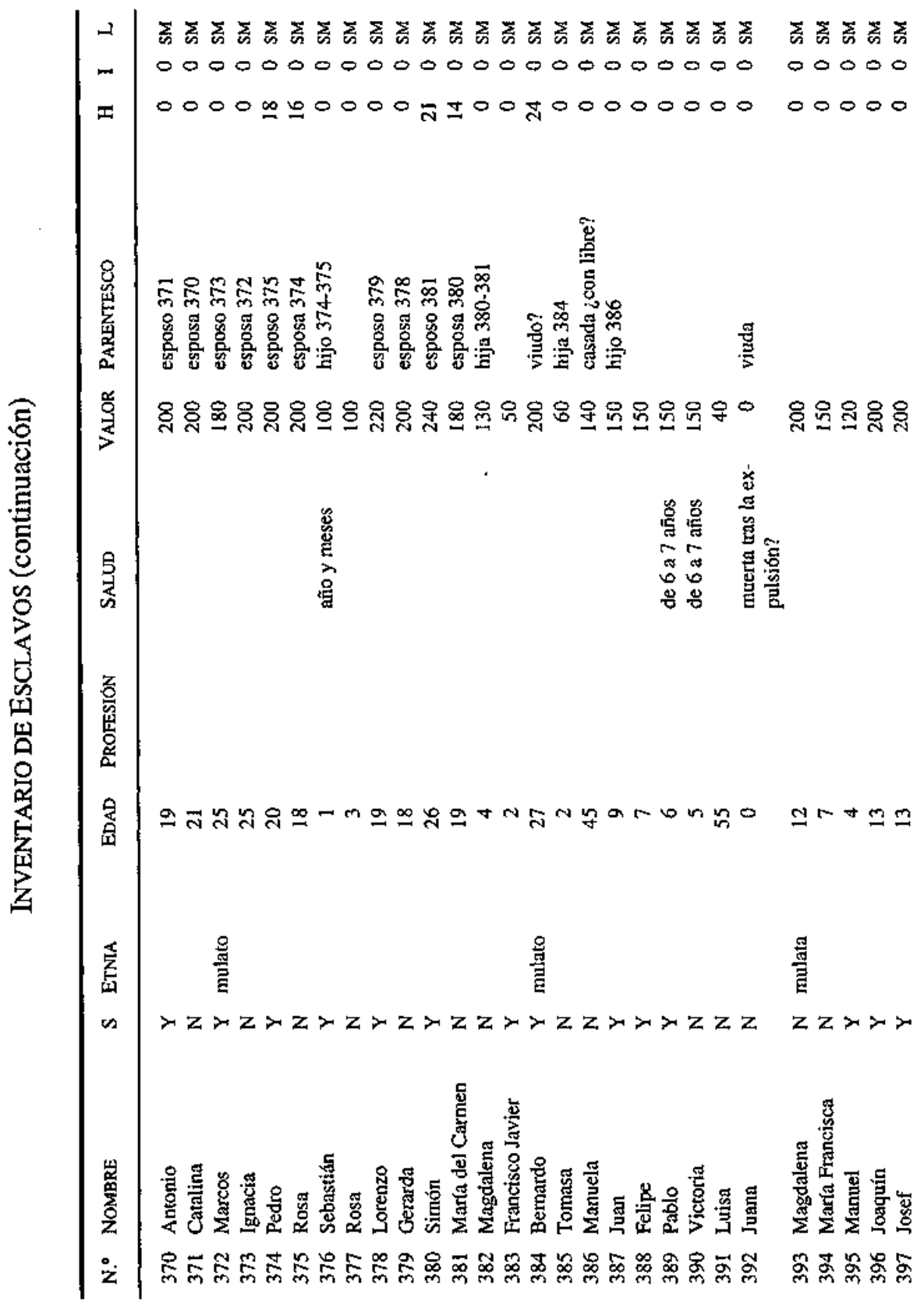




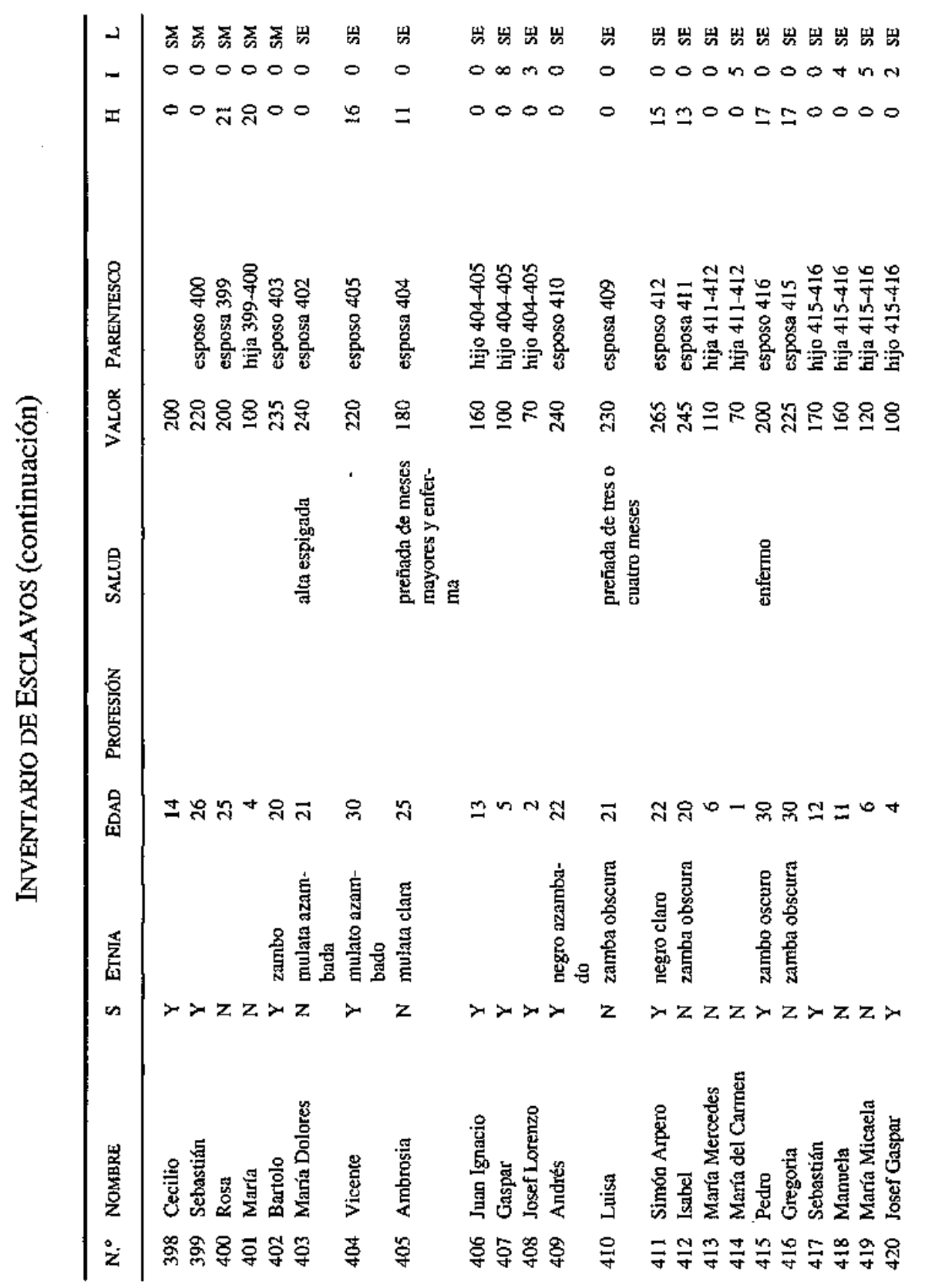

Missionalia Hispanica

Hispania Sacra 48 (1996) 


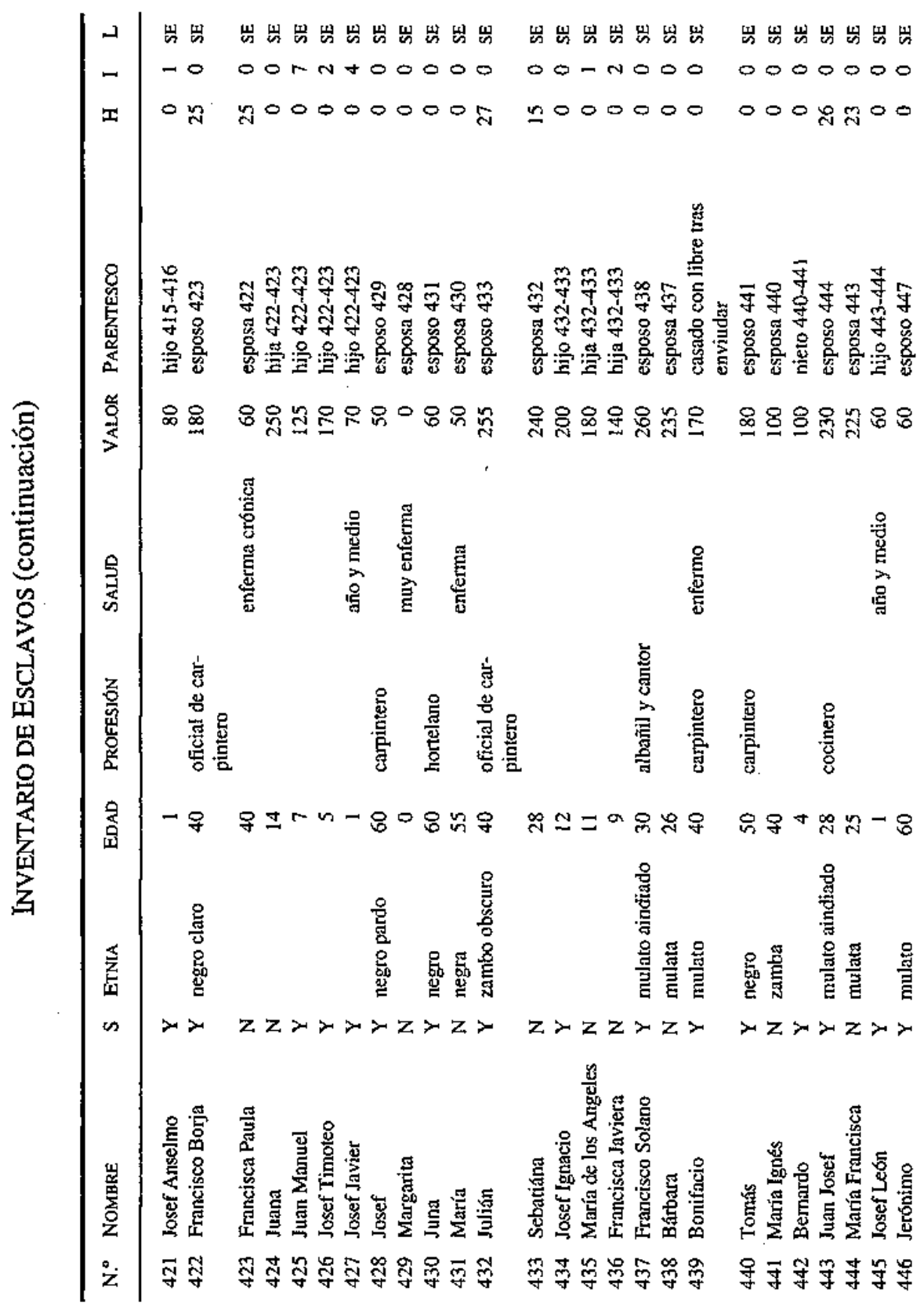

Missionalia Hispanica Hispania Sacra 48 (1996) 


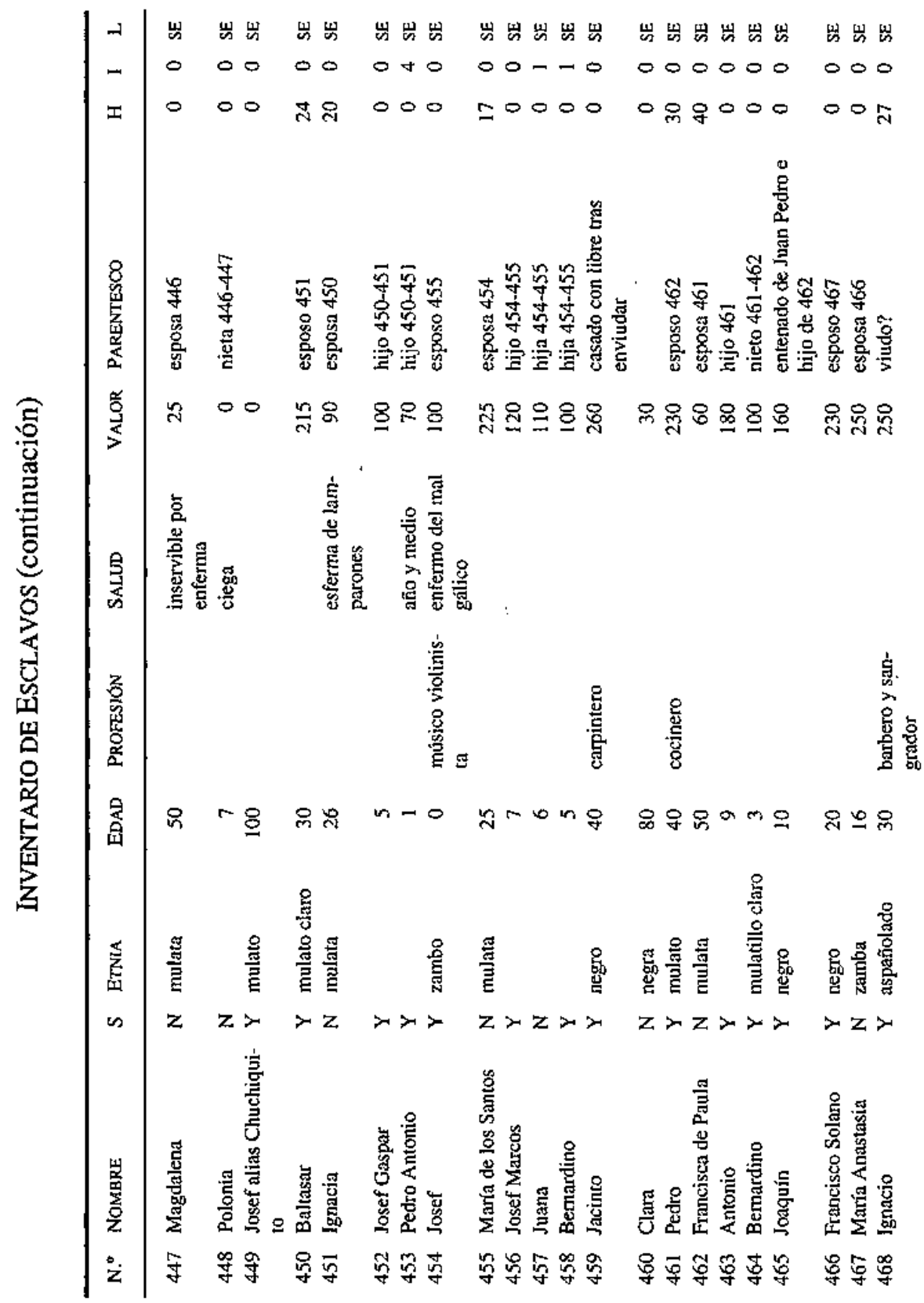

Missionalia Hispanica

Hispania Sacra 48 (1996) 
ESCLAVOS DE LAS TEMPORALIDADES (EL TUCUMÁN, 1768)

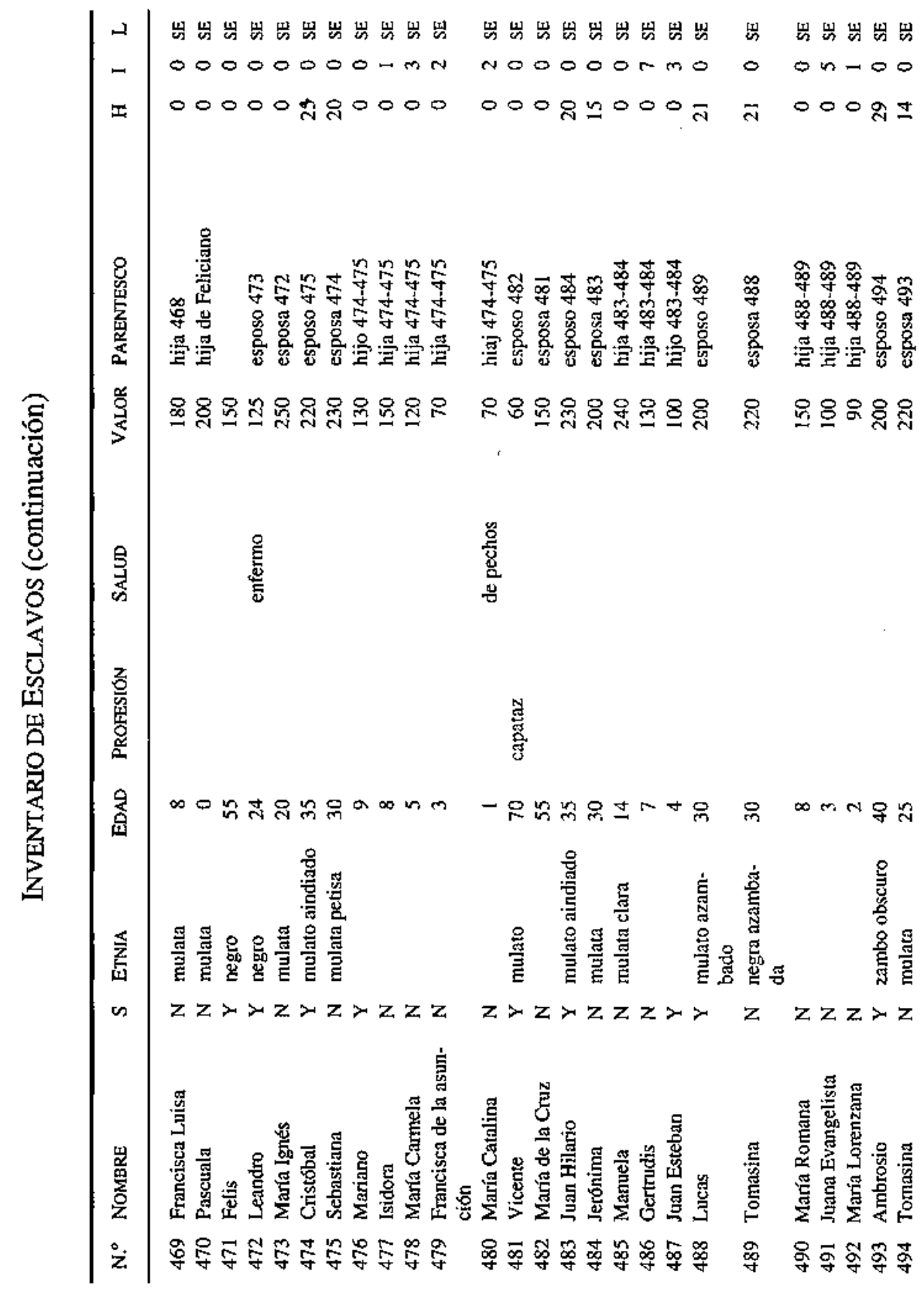

Missionalia Hispanica Hispania Sacra 48 (1996) 


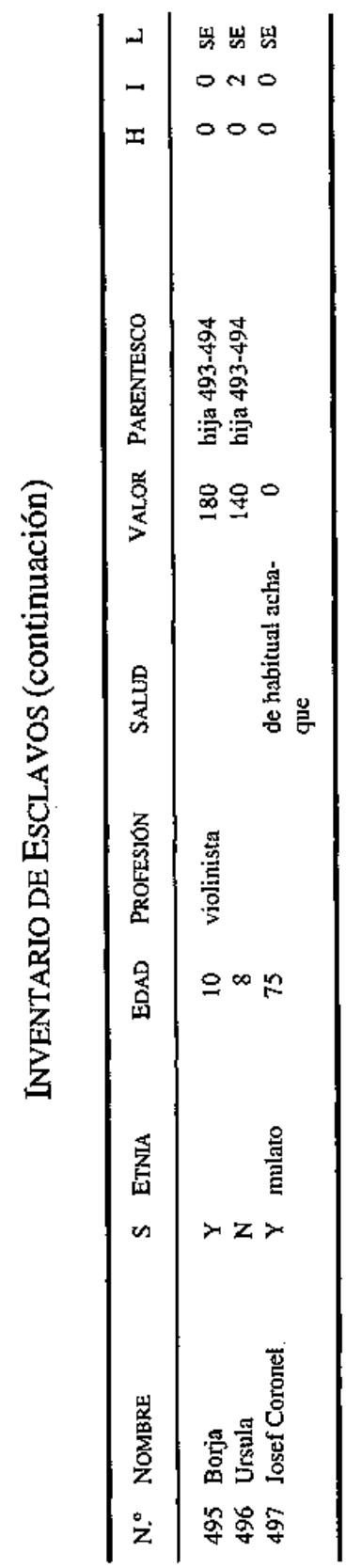

Missionalia Hispanica

Hispania Sacra 48 (1996) 